\title{
The Question of Employment Guidance on the Whole Process in Higher Vocational College
}

\author{
Zhang Cui-ying \\ Dept. Name of Organization: Hunan Railway Professional Technology College \\ Zhuzhou, Hunan, China, 412001 \\ emaill: sunny_zcy@163.com
}

Keywords: higher vocational college; the whole process; employment guidance

\begin{abstract}
It is in connection with benefit of the graduates, reflecting the quality and competition, and influencing recruit students and scope, and affecting subsistence and development, how to compete and take up an occupation rate the higher vocational college. It is absolutely necessarily course to set up the occupation rate that to enhance employment guidance for students. Employment guidance on the whole process may cultivate students' idea of occupation, and program their employment.
\end{abstract}

In recent years, the higher vocational education is developing rapidly, but the employment situation is increasingly grim when the popularization of higher education and the market economy have development. The higher vocational education undertakes to adapt to the task of all-round development. The technology talents have character、 wisdom、 healthy arts, and needs in the forefront of the production, construction, management, service. It is a indispensable target employment quality enhancing students' employment competitiveness of the higher vocational education. How the higher vocational college graduate's employment rate and employment levels, it relates to the vital interests of students, reflects the quality and competitiveness of higher vocational colleges, affects the school enrollment and scale of running school, and affects the school's survival and development. In the current, the employment and vocational colleges quality assessment often link, the employment rate is an important indicator of the specialty setting, teaching quality, the quality of students and school reputation in higher vocational colleges. So it is an essential part of the student's employment guidance for increase the rate of employment.

\section{1, the situation of employment guidance in the Higher Vocational Colleges the current}

The employment guidance work started late than abroad in our country, especially it is not also universal in higher vocational colleges., the employment guidance work could not in a proper position that due to historical and practical reasons For many higher vocational college. There isn't employment guidance on the whole process in higher vocational colleges, or is just at the beginning. A lot of employment guidance is mainly aimed at the interview skills or self guidance, isn't to further students' thoughts, is traditional and single. The teacher teaching for a task and the student study for credit, teachers' teaching and students' learning are passive in higher vocational colleges。

The work of employment guidance in Higher Vocational Colleges in China are confronted with the following problems: (1) surface, i.e. only teach students some interview techniques and methods; light substance, not pay attention to the students' attitude towards employment, as well as their state of mind and inner world. (2) the heavy assault, namely about employment skills courses or lectures provided mainly before graduation; light penetration, that is not the occupation guidance should be the whole university stage through students'. (3) the immediate, namely the schools only pay attention to the students out, find the light receiving unit; long term, which does not consider student's employment quality, forming a waste of talent. The employment guidance to ignore the personality development of students, psychological counseling, the conception of employment guidance, therefore, lead to the work of employment guidance and students cannot obtain good 
recognition, and the whole process employment guidance to students from the first grade to graduate school in the process of employment, through various forms of education, for the student employment services, to help students to establish a correct concept of occupation, understand the employment policy, master employment skills, to cultivate students' employment competition ability, enhance the quality of employment.

\section{2, the significance to carry out the whole process employment guidance in Higher Vocational Colleges}

(a) the whole process employment guidance can better cultivate students' correct employment outlook

The correct employment concept formation is a gradual process, rather than through a few sessions can be formed or changed, the whole process employment guidance in higher vocational college students three years of university life, in time, help students through the employment guidance, their observation and understanding and form a correct view of employment. In comparison, the students in higher vocational colleges because of the higher occupation education understanding is deep and shallow, at graduation psychology is more volatile, and through the long time consideration, some ideas about employments tend to mature, so as not to make hasty, wrong decision in the short time before graduation.

(b) the whole process employment guidance can help students plan their occupation employment

The whole process employment guidance and only to graduate employment guidance, the time is longer, the content is more rich, can help students to understand the development trend of the professional and they are learning, and rational planning their own occupation employment, and with the deepening and thought on their studies to understand the maturity further, can revise their occupation employment planning, employment and future ready.

\section{3, the implementation of whole process employment guidance}

(a) the implementation of the time

The whole process employment guidance from the beginning until the end of the freshmen, graduate students, at the time it runs through from the first grade to the third grade.

(b) the content of implementation

The whole process employment guidance in higher vocational students throughout the three years of study, life, the time is more abundant, more conducive to broaden employment guidance content, from the concept of employment, employment skills, employment decision-making, employment ability, occupation quality, employment policy, employment situation and employment preparation and other aspects of education, ready for their employment and future development. In three years of employment guidance should be interconnected, interrelated, forming a relatively complete system of employment guidance. At the same time for different grade students, the employment guidance contents are different.

On the first grade students mainly focus on the higher occupation education and science education, students can be more understanding of higher occupation education, understand their own major, and the development prospect of professional. Is mainly restricted by the traditional concept, many students lack of understanding of occupation education, do not understand the higher occupation education is an important part of higher education in our country, is the direct transformation of science and technology into productivity.

For the second grade students are mainly focused on the occupation quality, occupation ability education, so that they understand the professional employment situation and the relevant personnel requirements, promote them to improve their theoretical knowledge and practical operation ability, in addition, to cultivate students professional ethics, broaden their knowledge, exercise their interpersonal communication, adaptation, teamwork, ability to engage in any occupation are indispensable key. 
For the third grade students in the graduating class focuses on the concept of employment, employment skills, employment decision-making, employment skills, relevant law, employment policy, employment situation and employment preparation and other aspects of education, so that they are ready to start their own occupation employment, find a suitable for their own occupation, and reasonable matching job.

(c) the implementation form

a) employment guidance course

Curriculum as one of the important means to realize the teaching purpose, has broad and narrow sense, the narrow sense refers to the school curriculum system is constructed according to the certain education goal in all subjects and all kinds of education, teaching activities. The school personnel training is the main way of teaching, curriculum is the content in teaching activities and the implementation process (or style) of unity, is the means to achieve the aims of education. It can therefore be the reasonable curriculum, to promote full employment guidance. Employment guidance course mainly focuses on the employment related knowledge to teach students. Note that the traditional teaching methods emphasize system, the integrity of knowledge, not too suitable employment guidance course teaching, to take a variety of forms in teaching methods, establish the dominant position of students in teaching activities, stimulate their learning employment knowledge, guide them to independent thinking.

b) some activities of employment guidance

In addition to offer courses of employment guidance, but also through the development of rich and employment guidance activities related to the classroom teaching, combined with the practice of extra-curricular activities, such as and employment guidance related speech contests, debate competition, entrepreneurship competition, in order to stimulate the students' employment guidance related knowledge, a more profound. Reflection on employment, employment confidence, change is not the correct idea of choosing a job.

c) public lecture of employment guidance

Higher vocational colleges through irregular about employment guidance lectures to the students, propaganda, explain the employment policy, employment situation analysis. To help students get employment mentality, overcome various employment mental obstacles, such as inferiority of cowardice, blind confidence, eager for quick psychological, strengthen students' hardship consciousness, to face the social reality, proactive, strong practical, dare to compete, correctly treat the employment mentality of frustration.

d) experience activities of employment practice

To enable students to experience the employment scene atmosphere, can not carry out regular employment practice experience activity, such as the recruitment site visits, on-site recruitment simulation. By carrying out the employment practice experience activity, can train students job skills, such as understanding the material job writing, selling their skills, signing procedures and the rights, obligations and other matters needing attention. Combining theory with practice, to stimulate students interest in learning.

e) web site of employment guidance

The network has the advantages of convenient, fast, and now many vocational colleges have their own campus network, can set up a special employment guidance website on the campus, for students to the use of the internet. Can open multiple and employment in the website guidance related columns, such as recruitment information, job search skills, policies and regulations, psychological counseling, employment guidance, so that students can understand the latest information of obtain employment, learn some employment knowledge, experience and the exchange of students, and help them solve the problem of employment., even can carry out the psychological test free for the school's students, such as occupation interest test, comprehensive ability test, personality test, to help students in self understanding, self understanding. 


\section{References}

[1] Cheng Feng. Higher vocational education to implement whole process employment guidance mode approach [J]. Journal of Jining Normal College, 2004 (4): 73-74

[2] Yu Hongxiu. Journal of colleges and universities should carry out the whole process employment guidance [J]. Longyan Teachers College, 2004 (6): 122-124

[3]Lin Shifeng . Construction of Heilongjiang higher education study of college students employment guidance system under the new situation [J]. Heilongjiang higher education research, 2004 (10): 63-64

[4] Wang Benxian. On the people-oriented personalized employment guidance [J]. China occupation technology education,2007 (09) : 28-30

[5] Wang Baoyi. Personalized employment guidance to explore [J]. China occupation technology education, 2008 (03): 19-21 